\title{
El impulso de los programas de cumplimiento normativo: entre la promoción y la imposición
}

\section{Michael Luyo Castañeda ${ }^{(*)}$}

Abogado por la Universidad Nacional Mayor de San Marcos. Maestría en Derecho Administrativo Económico en la Universidad del Pacíico. Diplomado en Libre Competencia de la Universidad Adolfo Ibáñez, Chile.

Docente en la Escuela Nacional de Defensa de la Competencia y de la Protección del Instituto Nacional de Defensa de la Competencia y de la Protección de la Propiedad Intelectual.

SUMARIO:

I. Introducción.

II. La promoción de los programas de cumplimiento normativo.

1. La naturaleza voluntaria de los programas de cumplimiento normativo.

2. La promoción de los programas de cumplimiento normativo en el derecho comparado.

2.1. La apatía de la Unión Europea respecto de los programas de cumplimiento normativo.

2.2. La relevancia de los programas de cumplimiento normativo para el Departamento de Justicia de los Estados Unidos.

2.3. La visión del Tribunal de Defensa de la Libre Competencia de Chile sobre la importancia de los programas de cumplimiento normativo.

3. La promoción de los programas de cumplimiento normativo como un atenuante en la graduación de sanciones.

III. La imposición de los programas de cumplimiento normativo.

1. Las medidas correctivas ordenadas por entidades de la Administración Pública.

2. El camino para la correcta imposición de los programas de cumplimiento normativo como medidas correctivas.

IV. Comentarios finales.

$\left(^{*}\right.$ Dedicado a mis amados padres Alejandro y Lucy, con mucho cariño y admiración a ambos. 


\section{RESUMEN:}

En el presente artículo, el autor explora las formas en que la Administración Pública ha venido impulsando la implementación de programas de cumplimiento normativo en materia de libre competencia y protección al consumidor. Así, toma como referencia el carácter inicialmente voluntario de estos programas, para luego analizar el tratamiento normativo y jurisprudencial en la Unión Europea, Estados Unidos, Perú y Chile. Finalmente, adopta una postura crítica frente a la imposición de aquellos programas como medidas correctivas, formulando una serie de recomendaciones para una mejor actuación de la Administración Pública.

Palabras clave: Compliance, cumplimiento normativo, Administración Pública, impulso, imposición, INDECOPI.

\footnotetext{
ABSTRACT:

In this article, the author explores the ways in which the Public Administration has been promoting the implementation of regulatory compliance programs in the area of free competition and consumer protection. Thus, he takes as a reference the initially voluntary nature of these programs, and then analyzes the regulatory and jurisprudential treatment in the European Union, the United States, Peru and Chile. Finally, he adopts a critical stance against the imposition of these programs as corrective measures, formulating a series of recommendations for a better performance of the Public Administration.

Keywords: Compliance, regulatory compliance, Public Administration, promotion, imposition, INDECOPI.
}

\section{INTRODUCCIÓN}

En los últimos años, en nuestro país se ha impulsado el cumplimiento de las normas por parte de los agentes económicos mediante la implementación de programas de cumplimiento normativo al interior de las empresas. En particular, en las materias de libre y leal competencia, así como en protección al consumidor, se destaca la importancia de tales programas, así como los incentivos que tienen los mencionados agentes para su implementación.

Siendo ello así, resulta necesario explorar las formas cómo las entidades de la Administración Pública están impulsando la implementación de los programas de cumplimiento normativo. En particular, se han observado dos tipos de métodos: el primero, a través del método "zanahoria" —en términos más técnicos, se informa a las empresas de las ventajas y beneficios que tendrían tras la implementación de estos programas, a efectos que las mismas opten por su implementación de manera voluntaria-; $y$, Fernández, (Barcelona: Atelier, 2013), 43-76. cual se impone la implementación a través de mandatos de medidas correctivas.

Al respecto, procuraremos comprender ambos métodos que tienen las entidades de la Administración Pública para impulsar la implementación de los programas de cumplimiento normativo, conociendo su progreso en nuestro sistema jurídico, prestando especial atención a la normativa en materia de libre competencia, protección al consumidor, así como leal competencia y publicidad.

\section{LA PROMOCIÓN DE LOS PROGRAMAS DE CUMPLIMIENTO NORMATIVO}

\section{La naturaleza voluntaria de los progra- mas de cumplimiento normativo.}

Los programas de cumplimiento normativo pueden ser genéricamente definidos como aquellos cuerpos normativos en los que se recogen sistemas empresariales internos de gestión de riesgos dirigidos a la minimización de las infracciones normativas en el seno de la empresa. ${ }^{1}$

1. Ivó Coca Vila, "¿Programas de cumplimiento como forma de autorregulación regulada?", en Criminalidad de empresa y Compliance. Prevención y reacciones corporativas. Dir. Jesús-María Silva Sánchez, Coord. Raquel Montaner 
En particular, tales programas son un mecanismo de autorregulación, los cuales consisten en directrices autonómicas que buscan asegurar que las empresas planifiquen el cumplimiento de los deberes y obligaciones que el ordenamiento jurídico establece, a fin de que cumplan efectivamente con las mismas y monitoreen el resultado de tal cumplimiento, retroalimentando información en aras de la consolidación de procesos de mejora continua y sostenible. ${ }^{2}$

De este modo, los programas de cumplimiento normativo son un mecanismo de autorregulación de la persona jurídica que implica la adopción sistemática, organizada y sostenible de medidas y procesos internos con la finalidad de que la empresa cumpla con el marco jurídico vigente $y$, de este modo, prevenir y mitigar razonablemente la comisión ilícitos penales o administrativos. $^{3}$

El esquema autorregulatorio de tales programas evidencia su naturaleza esencialmente voluntaria. Ello, considerando que la autorregulación en sentido estricto hace referencia a aquellos supuestos en los que es el propio agente económico el que se dota de un sistema de regulación interno, absolutamente al margen de los poderes públicos; esto es, sin que exista intervención pública alguna dirigida a fomentar, imponer o completar — directa o indirectamente- la autorregulación interna. ${ }^{4}$
De esta manera, los programas de cumplimiento normativo son sumamente beneficiosos para las empresas, pues tienen amplias ventajas para ellas, tales como la prevención de incumplimientos a deberes y obligaciones que el ordenamiento jurídico establece y los costos que estos generan, la mejora reputacional y, de ADMINISTRATIVo ser el caso, la reducción de las multas.

\section{La promoción de los programas de cum- plimiento normativo en el derecho com- parado.}

A nivel comparado la promoción de los programas de cumplimiento resulta variado. Si bien se resalta su importancia, no significa que por su implementación se debe dar un trato especial a las empresas que a pesar de su implementación, han incumplido las normas. ${ }^{5}$

\subsection{La apatía de la Unión Europea respecto a los programas de cumplimiento normativo.}

La guía "La importancia de cumplir" - "Compliance Matters" - tiene como finalidad ayudar a las empresas de la Unión Europea para que eviten problemas y permitan garantizar el cumplimiento de las normas de competencia. En dicho documento se destaca que la mera existencia de los programas de cumplimiento normativo no implica la existencia de una circunstancia atenuante o una justificación de la reducción de la sanción impuesta al agente infractor a la normativa. ${ }^{6}$

2. Javier Pazos Hayashida y Andrea Vega Talledo, "Autorregulación y programas de cumplimiento empresarial en materia de publicidad comercial y protección al consumidor", Derecho PUCP 85 (2020): 175-202.

3. Giuliana Zúñiga Diaz y Luis Enrique Vilca Ravelo, “La Implementación de un Programa de Cumplimiento Efectivo como Eximente o Atenuante de Responsabilidad por Infracciones Administrativas", Derecho \& Sociedad 54 (2020): 397-412.

4. Carlos Alza Barco, “Autorregulación. Apuntes Conceptuales”, Derecho \& Sociedad 36 (2011): 74-78.

5. Para efectos del presente artículo, daremos principal énfasis a aquellas experiencias relacionadas al derecho de la competencia, dado que existe un mayor desarrollo en dicha materia.

6. Dirección General para la Competencia de la Comisión Europea, La importancia de cumplir. Qué pueden hacer las compañías para respetar mejor las normas de competencia de la UE (Luxemburgo: Oficina de Publicaciones de la Unión Europea, 2012), 19. 
De hecho, a nivel empírico, se destacó que no se tiene una idea clara de la frecuencia con la que los programas de cumplimiento normativo previenen las infracciones en materia de libre competencia en la Unión Europea.

En ese sentido, si bien existen quienes respaldan la necesidad de brindar una recompensa a las empresas por la implementación de los programas de cumplimiento, ${ }^{8}$ lo cierto es que la jurisprudencia del Tribunal de Justicia Europeo considera que tales programas no deben ser tomados en cuenta al momento de determinar la sanción a aplicar a los agentes económicos infractores. ${ }^{9}$

De esta manera, resulta claro que a nivel de la Unión Europea se considera a los programas de cumplimiento normativo como mecanismos de autorregulación, los cuales si bien deben ser promovidos, no son suficientes para reducir las sanciones administrativas por el incumplimiento normativo.

\subsection{La relevancia de los programas de cum- plimiento normativo para el Departa- mento de Justicia de los Estados Unidos.}

En la guía denominada Evaluation of Corporate Compliance Programs in Criminal Antitrust Investigations de la División Antitrust del Departamento de Justicia de los Estados Unidos se reconoce la importancia de los programas de cumplimiento normativo para prevenir y detectar las infracciones en materia de libre competencia. ${ }^{10}$

En dicha guía se destaca que cuando se toma la decisión de acusar a una empresa, los fiscales de la División Antitrust del Departamento de Justicia

En dicho documento se señala expresamente lo siguiente:

"Al fijar el nivel de las multas, se tiene debidamente en cuenta la situación específica de una compañía. Pero la mera existencia de un programa de cumplimiento no se considerará circunstancia atenuante. Tampoco la implantación de un programa de cumplimiento se considerará argumento válido para justificar una reducción de la multa tras la investigación de una infracción. Debe, no obstante, ser fomentada por las autoridades de competencia como medio preventivo para evitar que se produzca o pueda repetirse el comportamiento ilegal" —el subrayado es nuestro-.

7. Wouter P. J. Wils, "Antitrust Compliance Programmes \& Optimal Antitrust Enforcement", Journal of Antitrust Enforcement 1(1), (2013): 52-81. Disponible en SSRN: https://ssrn.com/abstract=2176309

8. Damien Geradin, "Antitrust Compliance Programmes \& Optimal Antitrust Enforcement: A Reply to Wouter Wils", Journal of Antitrust Enforcement 1(2), (2013). Disponible en SSRN: https://ssrn.com/abstract=2241452

9. Sentencia del Tribunal General —Sala Octava— de 13 de julio de 2011.

Schindler Holding Ltd y otros contra Comisión Europea.

"282. Por lo que respecta al fundamento del enfoque de la Comisión, ya se ha declarado que la adopción de un programa de adecuación por parte de la empresa interesada no obliga a la Comisión a conceder una reducción en atención a dicha circunstancia (sentencia BASF y UCB/Comisión, citada en el apartado 143 supra, apartado 52). Además, aunque es sin duda importante que una empresa tome medidas para impedir que los miembros de su personal cometan en el futuro nuevas infracciones del Derecho de la competencia de la Unión, la adopción de tales medidas en nada cambia la realidad de la infracción probada. La Comisión no está, pues, obligada a calificar ese elemento como una circunstancia atenuante, (...)" —el subrayado es nuestro-.

10. Departamento de Justicia — División de Libre Competencia de los Estados Unidos, Evaluation of Corporate Compliance Programs in Criminal Antitrust Investigation (Washington, D.C.: U.S. Department of Justice, 2019), 1, acceso el 18 de julio de 2021, https://www.justice.gov/atr/page/file/1182001/download.

En dicho documento se destaca lo siguiente:

"Antitrust compliance programs promote vigorous competition in a free market economy by creating a culture of good corporate citizenship within a company that seeks to prevent antitrust violations. Although an antitrust compliance program may not prevent every violation, an effective compliance program should be able to detect and address potential antitrust violations. (...) Indeed, a truly effective antitrust compliance program gives a company the best chance to obtain the significant benefits available under the Division's Corporate Leniency program." 
deben evaluar si corresponde recomendar una reducción de la sanción basada en la existencia de un programa de cumplimiento efectivo.

De hecho, la guía desarrolla los aspectos contenidos en las Sentencing Guidelines -reglas del Poder Judicial de determinación de la pena - para que un programa de cumplimiento efectivo puede ser considerado relevante al momento de recomendar una reducción de la sanción. ${ }^{11}$

\subsection{La visión del Tribunal de Defensa de la Li- bre Competencia de Chile sobre la impor- tancia de los programas de cumplimiento normativo.}

Ahora bien, cabe mencionar que, a nivel de derecho comparado, no solo se ha reconocido a los programas de cumplimiento como una circunstancia atenuante, sino como un eximente de responsabilidad.

En efecto, en la Sentencia N ${ }^{\circ} 167 / 2019$ del 28 de febrero de 2019, el Tribunal de Defensa de la Libre Competencia —TDLC, de Chile señaló que un programa de cumplimiento normativo cuya elaboración y ejecución reúne ciertas características mínimas, las cuales permiten calificar la ocurrencia de conductas ilícitas como hechos imposibles de haber sido prevenidas por el agente económico o evitar con la debida ADMINISTRATIVO diligencia y, por consiguiente, constitutivos de una causal eximente de responsabilidad. ${ }^{12}$

La promoción de los programas de cumplimiento por parte del TDLC ha llegado a tal nivel que acepta la opción de considerarlo como un eximente de responsabilidad.

Sin perjuicio de lo anterior, la Corte Suprema de Chile ha discrepado de lo afirmado por el TDLC respecto del rol que cumplen los programas de cumplimiento en materia de libre competencia, en el sentido que estos no constituyen eximentes de responsabilidad, pues para ser considerados como eximentes los mismos deben encontrarse expresamente regulados en la ley, cuestión que no ocurre con los programas de cumplimiento. ${ }^{13}$

Traducción libre del Editor:

"Los programas de cumplimiento de normas de libre competencia promueven la competencia vigorosa en una economía de libre mercado al crear una cultura de buena ciudadanía corporativa dentro de una compañía que busca prevenir violaciones de la normativa de libre competencia. A pesar de que un programa de cumplimiento de normas de libre competencia podría no prevenir todas las violaciones, un programa efectivo debería poder ser capaz de detectar y abordar posibles violaciones de la normativa de libre competencia. (...) En efecto, un programa de cumplimiento de normas de libre competencia verdaderamente eficaz otorga a la compañía la mejor oportunidad de obtener los sustantivos beneficios disponibles al amparo del programa de lenidad corporativa de la División."

11. Belén Tomic, "La valoración de los programas de compliance en el derecho comparado", Centro de Competencia de la Universidad Adolfo Ibáñez, 23 de junio de 2020, https://centrocompetencia.com/la-valoracion-de-los-programas-de-compliance-en-el-derecho-comparado/.

12. Sentencia $n^{\circ} 167 / 2019$ del 28 de febrero de 2019.

"Que en el derecho de la libre competencia, el diseño y aplicación de programas de cumplimiento yética, con las características que se indicarán, puede ser prueba manifiesta de aquel cuidado que permite al agente económico eximirse de responsabilidad por conductas anticompetitivas de sus trabajadores. En efecto, un programa cuya elaboración y ejecución reúne ciertos atributos mínimos permite calificar la ocurrencia de conductas ilícitas como hechos imposibles de haber podido prevenir o evitar con la debida diligencia y, por consiguiente, constitutivos de una causal eximente de responsabilidad; (...)" - el subrayado es nuestro-.

13. Belén Tomic, "Compliance en Latinoamérica: de dulce y agraz", Centro de Competencia de la Universidad Adolfo Ibáñez, 19 de agosto de 2020, https://centrocompetencia.com/compliance-en-latinoamerica-de-dulce-y-agraz/. 
3. La promoción de los programas de cumplimiento normativo como un atenuante en la graduación de sanciones.

El Instituto Nacional de Defensa de la Competencia y de la Protección de la Propiedad Intelectual - INDECOPI, a través de sus órganos funcionales, tiene la competencia para sancionar las siguientes conductas:

a) Infracciones administrativas en materia de protección al consumidor, conforme a lo establecido en la Ley 29571, Código de Protección y Defensa del Consumidor. Al respecto, existen dos tipos de procedimientos: (i) el procedimiento sumarísimo bajo la competencia del Órgano de Procedimientos Sumarísimos en primera instancia y la Comisión de Protección al Consumidor en segunda instancia; $y$, (ii) el procedimiento ordinario bajo la competencia de la Comisión de Protección al Consumidor en primera instancia y la Sala Especializada en Protección al Consumidor en segunda instancia. ${ }^{14}$

b) Infracciones administrativas en materia de leal competencia y publicidad, contenidas en el Decreto Legislativo 1044, Ley de Represión de la Competencia Desleal. Al respecto, la Comisión de Fiscalización de la Competencia Desleal es la autoridad competente en primera instancia y la Sala Especializada en Defensa de la Competencia es la autoridad competente en segunda instancia. ${ }^{15}$

c) Infracciones administrativas en materia de libre competencia, contenidas en el Decreto Legislativo 1034, Ley de Represión de Conductas Anticompetitivas. Al respecto, la Comisión de la Libre Competencia es la autoridad competente en primera instancia y la Sala Especializada en Defensa de la Competencia es la autoridad competente en segunda instancia. ${ }^{16}$

Las autoridades competentes están promoviendo la implementación de los programas de cumplimiento normativo a través de la reducción de sanciones administrativas. En particular, se observa una clara tendencia a considerar la implementación de tales programas como posibles atenuantes cuando se realiza la graduación de las sanciones. Ello ha sido reconocido en diversas maneras, conforme se aprecia a continuación:

14. Ley 29571, Código De Protección y Defensa del Consumidor:

"Artículo 105.- Autoridad competente.

El Instituto Nacional de Defensa de la Competencia y de la Protección de la Propiedad Intelectual (Indecopi) es la autoridad con competencia primaria y de alcance nacional para conocer las presuntas infracciones a las disposiciones contenidas en el presente Código, así como para imponer las sanciones y medidas correctivas establecidas en el presente capítulo, conforme al Decreto Legislativo No 1033, Ley de Organización y Funciones del Indecopi. Dicha competencia solo puede ser negada cuando ella haya sido asignada o se asigne a favor de otro organismo por norma expresa con rango de ley. (...)"

15. Decreto Legislativo 1044, Ley de Represión de la Competencia Desleal:

"Artículo 6.- Cláusula general.

6.1.- Están prohibidos y serán sancionados los actos de competencia desleal, cualquiera sea la forma que adopten y cualquiera sea el medio que permita su realización, incluida la actividad publicitaria, sin importar el sector de la actividad económica en la que se manifiesten. (...)"

"Artículo 24.- Las autoridades.

24.1.- En primera instancia administrativa la autoridad es la Comisión, entendiendo por ésta a la Comisión de Fiscalización de la Competencia Desleal y a las Comisiones de las Oficinas Regionales del INDECOPI en las que se desconcentren las funciones de aquélla, según la competencia territorial que sea determinada.

Las Comisiones de las Oficinas Regionales serán competentes únicamente respecto de actos que se originen y tengan efectos, reales o potenciales, exclusivamente dentro de su respectiva circunscripción de competencia territorial.

24.2.- En segunda instancia administrativa la autoridad es el Tribunal, entendiendo por éste al Tribunal de Defensa de la Competencia y de la Protección de la Propiedad Intelectual del INDECOPI. (...)"

16. Decreto Supremo N 030-2019-PCM, Texto Único Ordenado de la Ley de Represión de Conductas Anticompetitivas: (Continúa en siguiente página) 


\section{Cuadro 1}

\begin{tabular}{|c|c|c|c|}
\hline Materia & Reconocimiento & Supuesto & Efecto \\
\hline $\begin{array}{l}\text { Protección al } \\
\text { Consumidor }\end{array}$ & $\begin{array}{l}\text { El artículo } 112 \text { de Ley } 29571, \text { Código } \\
\text { de Protección y Defensa del } \\
\text { Consumidor }^{17}\end{array}$ & $\begin{array}{l}\text { Programa } \\
\text { efectivo para el } \\
\text { cumplimiento } \\
\text { de la normativa } \\
\text { en materia de } \\
\text { protección al } \\
\text { consumidor. }\end{array}$ & $\begin{array}{l}\text { Circunstancia } \\
\text { atenuante para } \\
\text { la graduación } \\
\text { de la sanción. }\end{array}$ \\
\hline $\begin{array}{l}\text { Publicidad } \\
\text { Comercial }\end{array}$ & $\begin{array}{l}\text { El artículo } 12 \text { del Reglamento que } \\
\text { Promueve y Regula la Implementación } \\
\text { Voluntaria de Programas de } \\
\text { Cumplimiento Normativo en Materia } \\
\text { de Protección al Consumidor y } \\
\text { Publicidad Comercial, aprobado por } \\
\text { Decreto Supremo N }{ }^{\circ} 185-2019-\mathrm{PCM}^{18}\end{array}$ & $\begin{array}{l}\text { Programa } \\
\text { efectivo para el } \\
\text { cumplimiento } \\
\text { de la normativa } \\
\text { de publicidad } \\
\text { comercial. }\end{array}$ & $\begin{array}{l}\text { Circunstancia } \\
\text { atenuante para } \\
\text { la graduación } \\
\text { de la sanción. }\end{array}$ \\
\hline $\begin{array}{l}\text { Libre } \\
\text { Competencia }\end{array}$ & $\begin{array}{l}\text { Guía de Programas de Cumplimiento } \\
\text { de las Normas de Libre Competencia, } \\
\text { aprobado por Resolución N } 006- \\
\text { 2020/CLC-INDECOPI }\end{array}$ & $\begin{array}{l}\text { Programa } \\
\text { efectivo para el } \\
\text { cumplimiento } \\
\text { de la normativa } \\
\text { de libre compe- } \\
\text { tencia. }\end{array}$ & $\begin{array}{l}\text { Circunstancia } \\
\text { atenuante para } \\
\text { la graduación } \\
\text { de la sanción. }\end{array}$ \\
\hline
\end{tabular}

Fuente: Elaboración propia

"Artículo 1.- Finalidad de la presente Ley

La presente Ley prohíbe y sanciona las conductas anticompetitivas con la finalidad de promover la eficiencia económica en los mercados para el bienestar de los consumidores."

"Artículo 13.- Las autoridades de competencia

13.1. En primera instancia administrativa la autoridad de competencia es la Comisión, entendiendo por ésta a la Comisión de Defensa de la Libre Competencia del INDECOPI.

13.2. En segunda instancia administrativa la autoridad de competencia es el Tribunal, entendiendo por éste al Tribunal de Defensa de la Competencia y de la Protección de la Propiedad Intelectual del INDECOPI."

17. Ley 29571, Código de Protección y Defensa del Consumidor:

"Artículo 112.- Criterios de graduación de las sanciones administrativas.

Se consideran circunstancias atenuantes especiales, las siguientes:

(...)

4. Cuando el proveedor acredite que cuenta con un programa efectivo para el cumplimiento de la regulación contenida en el presente Código, para lo cual se toma en cuenta lo siguiente:

a. El involucramiento y respaldo de parte de los principales directivos de la empresa a dicho programa.

b. Que el programa cuenta con una política y procedimientos destinados al cumplimiento de las estipulaciones contenidas en el Código.

c. Que existen mecanismos internos para el entrenamiento y educación de su personal en el cumplimiento del Código. d. Que el programa cuenta con mecanismos para su monitoreo, auditoría y para el reporte de eventuales incumplimientos. 
Lo anterior evidencia que se ha reconocido la importancia de la implementación de los programas de cumplimiento normativo, promoviéndolos a través de la reducción de sanciones administrativas.

En relación con lo anterior, no resulta claro aún el nivel de relevancia que tendrían tales programas para reducir efectivamente las posibles conductas infractoras como para incentivar su implementación. De hecho, a nivel comparado no existe consenso sobre la necesidad de promover tales programas a través de la reducción de sanciones, conforme se explicó previamente.

Frente a ello, al haber elegido este esquema de promoción para la implementación de programas de cumplimiento, resulta necesario que se tengan claras las reglas y los incentivos que permitan atraer realmente a los agentes económicos, los cuales conocen que tales programas, como la propia humanidad, son falibles.

De hecho, en materia de libre competencia, una empresa que cumpla satisfactoriamente con los criterios establecidos en la Guía de Programas de Cumplimiento, la autoridad competente podrá otorgarle una reducción del $5 \%$ al $10 \%$ de la multa, lo cual resulta un incentivo importante que podría ampliarse, como ocurre en otros países que también lo promueven. ${ }^{20}$

De hecho, tal experiencia evidencia que en materias de protección al consumidor y publicidad no resultan claras las reglas y el nivel de beneficios económicos, lo cual podría generar una situación de incertidumbre para que los agentes económicos implementen voluntariamente los programas de cumplimiento normativo en tales materias.

\section{LA IMPOSICIÓN DE LOS PROGRAMAS DE CUMPLIMIENTO NORMATIVO}

\section{Las medidas correctivas ordenadas por las entidades de la Administración Pública.}

La potestad sancionadora de las entidades de la Administración Pública se encuentra estre-

\begin{abstract}
e. Que cuenta con mecanismos para disciplinar internamente los eventuales incumplimientos al Código.
$f$. Que los eventuales incumplimientos son aislados y no obedecen a una conducta reiterada."
\end{abstract}

18. Decreto Supremo № 185-2019-PCM, Reglamento que Promueve y Regula la Implementación Voluntaria de Programas de Cumplimiento Normativo en Materia de Protección al Consumidor y Publicidad Comercial: "Artículo 12. De la extensión de los programas de cumplimiento a la normativa de publicidad comercial Los proveedores pueden implementar programas de cumplimiento respecto de la normativa de publicidad comercial establecida en el Decreto Legislativo No 1044, Ley de Represión de la Competencia Desleal, los cuales consideran lo señalado en el presente reglamento, en lo que resulte aplicable. La existencia de programas de cumplimiento podrá constituir una circunstancia atenuante para la graduación de la sanción derivada de las eventuales infracciones al Decreto Legislativo No 1044, Ley de Represión de la Competencia Desleal."

19. Guía de Programas de Cumplimiento de las Normas de Libre Competencia:

"7.3. Graduación en el cálculo de la multa

A nivel comparado, se advierte la posibilidad de que la autoridad de competencia considere el hecho de que la empresa infractora haya desarrollado un Programa de Cumplimiento efectivo en su organización de manera previa a la ocurrencia de una infracción, como un factor para la graduación de la multa aplicable.

(...)

De manera similar, el hecho de que la empresa haya contado con un Programa de Cumplimiento efectivo cuando se cometió la infracción será valorado como un factor de graduación de la multa a imponer.

(...)

Bajo estas premisas, cuando el Programa de Cumplimiento de una empresa cumpla satisfactoriamente con los tres criterios antes establecidos, la Comisión podrá otorgarle una reducción del $5 \%$ al 10\% de la multa que le hubiese resultado aplicable. Dicho porcentaje variará en función a la oportunidad en la que la empresa reportó la infracción a la autoridad y a la efectividad de las acciones adoptadas en el marco de su Programa de Cumplimiento."

20. Por ejemplo, en Chile, el TDLC aplicó respecto de una empresa infractora una rebaja prudencial a la multa base ascendente a un 15\%, en la Sentencia N 167/2019 del 28 de febrero de 2019. 
chamente ligada con los principios de legalidad y tipicidad recogidos en el artículo 248 del Texto Único Ordenado de la Ley 27444, Ley del Procedimiento Administrativo General. Las entidades deben guiar su actuación considerando tales principios. ${ }^{21}$

De manera complementaria, en los procedimientos sancionadores se evalúa si los agentes económicos han infringido deberes jurídicos preexistentes, para lo cual las entidades de la Administración Pública requieren realizar una acusación en contra de tales agentes para que puedan ejercer su derecho de defensa. ${ }^{22}$

Lo anterior resulta relevante, pues se ha recogido expresamente en la Ley del Procedimiento Administrativo General que los administrados cuentan con el derecho de ser notificados de los hechos que se le imputen a título de cargo, la calificación de las infracciones que tales hechos pueden constituir y la expresión de las sanciones que, en su caso, se le pudiera imponer. ${ }^{23}$

De esta manera, resulta claro que los investigados deben defenderse de una imputación ADMINISTRATIVO especifica en su contra. En el supuesto que se determine la responsabilidad administrativa de tales sujetos, se debe sancionar únicamente la conducta investigada, así como adoptar las medidas correctivas en relación con tal conducta.

En este punto, cabe mencionar que las medidas correctivas se caracterizan por ser actos de gravamen y autónomos que están sujetos al principio de legalidad, dictadas por las entidades de la Administración Pública ante la comisión de algún ilícito, para, independientemente

21. Decreto Supremo Nº04-2019-JUS, Texto Único Ordenado de la Ley 27444, Ley del Procedimiento Administrativo General:

"Artículo 248.- Principios de la potestad sancionadora administrativa

La potestad sancionadora de todas las entidades está regida adicionalmente por los siguientes principios especiales:

1. Legalidad.- Sólo por norma con rango de ley cabe atribuir a las entidades la potestad sancionadora y la consiguiente previsión de las consecuencias administrativas que a título de sanción son posibles de aplicar a un administrado, las que en ningún caso habilitarán a disponer la privación de libertad.

(...)

4. Tipicidad.- Solo constituyen conductas sancionables administrativamente las infracciones previstas expresamente en normas con rango de ley mediante su tipificación como tales, sin admitir interpretación extensiva o analogía. Las disposiciones reglamentarias de desarrollo pueden especificar o graduar aquellas dirigidas a identificar las conductas o determinar sanciones, sin constituir nuevas conductas sancionables a las previstas legalmente, salvo los casos en que la ley o Decreto Legislativo permita tipificar infracciones por norma reglamentaria. (....)"

22. Al respecto, en la Sentencia recaída en el Expediente $\mathrm{N}^{\circ}$ 03987-2010-PHC/TC, el Tribunal Constitucional ha destacado lo siguiente:

"La trascendencia constitucional del derecho a ser informado de la imputación reside en que su configuración y existencia posibilita el ejercicio real y efectivo del derecho de defensa, entendido como el derecho a contradecir los cargos, ofrecer pruebas de descargo y de alegar lo que se crea conveniente en defensa de sus intereses. Si no existe imputación o si existiendo no se le informa a la persona acerca del cargo (hecho, calificación jurídica y evidencia) que pesa en su contra, simplemente el ejercicio de derecho de defensa será estéril y su valor ridículo desde la perspectiva legal y constitucional, pues no se sabrá nunca a ciencia cierta acerca del contenido, núcleo o límites de lo que la persona deberá conocer para luego refutar" —el subrayado es nuestro-.

23. Decreto Supremo N 004-2019-JUS, Texto Único Ordenado de la Ley 27444, Ley del Procedimiento Administrativo General:

"Artículo 254.- Caracteres del procedimiento sancionador

254.1 Para el ejercicio de la potestad sancionadora se requiere obligatoriamente haber seguido el procedimiento legal o reglamentariamente establecido caracterizado por:

(...)

3. Notificar a los administrados los hechos que se le imputen a título de cargo, la calificación de las infracciones que tales hechos pueden constituir y la expresión de las sanciones que, en su caso, se le pudiera imponer, así como la autoridad competente para imponer la sanción y la norma que atribuya tal competencia." 
de la sanción que corresponda, reestablecer al estado anterior las cosas o reparar la legalidad afectada mediante la cancelación o reversión de los efectos externos producidos. ${ }^{24}$

Finalmente, cabe recordar que las medidas correctivas deben estar previamente tipificadas en una norma con rango de ley, ser razonables y ajustarse a la intensidad, proporcionalidad y necesidades de los bienes jurídicos tutelados que se pretenden garantizar en cada supuesto concreto, de acuerdo con los artículos 246 y 251 del Texto Único Ordenado de la Ley 27444, Ley del Procedimiento Administrativo General. ${ }^{25}$

\section{El camino para la correcta imposición de los programas de cumplimiento normati- vo como medidas correctivas.}

Desde hace algunos años se ha impuesto la implementación de programas de cumplimiento normativo como una medida correctiva frente la infracción de normas. Si bien en materia de libre competencia se ha visto dicha tendencia, las materias de protección al consumidor y leal competencia podrían verse también influenciadas por ella. Por lo que resulta necesario conocer el camino que se ha transitado para andar bien.

En materia de libre competencia, a partir del 2016, la Comisión ha dictado numerosas medidas correctivas consistentes en la implementación de programas de cumplimiento para las empresas involucradas en cárteles, conforme se observa a continuación:

\section{Cuadro 2}

\section{Conducta infractora}

Fijación concertada de precios de productos farmacéuticos y afines.

Fijación concertada de precios y otras condiciones comerciales del papel higiénico y del papel tissue.

Fijación concertada del precio de venta del GLP vehicular.

Fijación concertada de precio del balón de gas.

Fijación concertada del precio de venta del GLP vehicular.

Fijación concertada del precio de venta del diésel y gasoholes.

\section{Resolución}

078-2016/CLC-INDECOPI del 12 de octubre de $2016^{26}$

010-2017/CLC-INDECOPI del 22 de marzo de $2017^{27}$

099-2017/CLC-INDECOPI del 7 de diciembre de $2017^{28}$

100-2017/CLC-INDECOPI del 18 de diciembre de $2017^{29}$

101-2017/CLC-INDECOPI del 18 de diciembre de $2017^{30}$

049-2018/CLC-INDECOPI del 3 de setiembre de $2018^{31}$

Fuente: Indecopi

24. Juan Carlos Morón Urbina, "Los actos-medidas (medidas correctivas, provisionales y de seguridad) y la potestad sancionadora de la Administración", Revista de Derecho Administrativo 9 (2010): 157.

25. Decreto Supremo № 004-2019-JUS, Texto Único Ordenado de la Ley 27444, Ley del Procedimiento Administrativo General: 
La posibilidad de ordenar medidas correctivas para la implementación de programas de cumplimiento no se encontraba recogida originalmente en el Decreto Legislativo 1034. Por tal motivo, resulta posible intuir que su imposición no cumplía con lo dispuesto en los artículos 246 y 251 del Texto Único Ordenado de la Ley 27444, Ley del Procedimiento Administrativo General, los cuales establecen que una medida correctiva requiere encontrarse en una norma con rango de ley para su imposición al infractor. Sin embargo, el 7 de setiembre de 2018 se publicó en el Diario Oficial "El Peruano" el Decreto Legislativo 1396, por el cual se modificó la Ley de Represión de Conductas Anticompetitivas, introduciendo en la normativa de libre competencia la facultad de la Comisión de imponer como medida correctiva el desarrollo de programas de capacitación y de eliminación de riesgos de incumplimiento de la normativa sobre libre competencia.

En este punto, es importante mencionar que la sola posibilidad de ordenar la implementación de programas de cumplimiento no resulta sufi- ADMINISTRATIVO ciente para que se pueda ordenar tal medida, pues como se ha mencionado resulta necesario que el mandato de medida correctiva sea razonable y ajustado a la intensidad, proporcionalidad y necesidades del bien jurídico tutelado que se pretende garantizar.

Siendo ello así, la autoridad, de ser el caso, requiere motivar el mandato de medida correctiva, observando el principio de razonabilidad, ${ }^{31}$ a fin de que la implementación de programas

"Artículo 246.- Medidas cautelares y correctivas

Las entidades solo podrán dictar medidas cautelares y correctivas siempre que estén habilitadas por Ley o Decreto Legislativo y mediante decisión debidamente motivada y observando el Principio de Proporcionalidad."

"Artículo 251.- Determinación de la responsabilidad

251.1 Las sanciones administrativas que se impongan al administrado son compatibles con el dictado de medidas correctivas conducentes a ordenar la reposición o la reparación de la situación alterada por la infracción a su estado anterior, incluyendo la de los bienes afectados, así como con la indemnización por los daños y perjuicios ocasionados, las que son determinadas en el proceso judicial correspondiente. Las medidas correctivas deben estar previamente tipificadas, ser razonables y ajustarse a la intensidad, proporcionalidad y necesidades de los bienes jurídicos tutelados que se pretenden garantizar en cada supuesto concreto.

(...)" - el subrayado es nuestro-.

26. Acto administrativo confirmado por Resolución N0738-2017/SDC-INDECOPI del 27 de diciembre de 2017.

27. Acto administrativo confirmado por Resolución Nº 0190-2018/SDC-INDECOPI del 4 de septiembre de 2018.

28. Acto administrativo confirmado por Resolución Nº 0225-2019/SDC-INDECOPI del 10 de diciembre de 2019.

29. Acto administrativo confirmado por Resolución N 0157-2019/SDC-INDECOPI del 26 de agosto de 2019.

30. Acto administrativo confirmado por Resolución N 0171-2019/SDC-INDECOPI del 12 de setiembre de 2019.

31. Decreto Supremo Nº 004-2019-JUS, Texto Único Ordenado de la Ley 27444, Ley del Procedimiento Administrativo General:

Título Preliminar

"Artículo IV. Principios del procedimiento administrativo

1. El procedimiento administrativo se sustenta fundamentalmente en los siguientes principios, sin perjuicio de la vigencia de otros principios generales del Derecho Administrativo:

(...)

1.4. Principio de razonabilidad.- Las decisiones de la autoridad administrativa, cuando creen obligaciones, califiquen infracciones, impongan sanciones, o establezcan restricciones a los administrados, deben adaptarse dentro de los límites de la facultad atribuida y manteniendo la debida proporción entre los medios a emplear y los fines públicos que deba tutelar, a fin de que respondan a lo estrictamente necesario para la satisfacción de su cometido.

(...)" 
de cumplimiento responda a lo estrictamente necesario para la satisfacción de su cometido.

Especialmente, la medida correctiva debe ser proporcional a la infracción que ha sido objeto de la acusación al agente económico, pues es tal acusación la cual ha sido objeto de defensa. Siendo ello así, ordenar la implementación de un programa de cumplimiento deberá considerar necesariamente las características del caso concreto y, en particular, la posibilidad de repetición de la conducta investigada y sancionada en el futuro si es que no se toma esta medida correctiva de naturaleza preventiva. ${ }^{32}$

\section{COMENTARIOS FINALES}

De acuerdo con lo antes expuesto, actualmente existen dos métodos para impulsar los programas de cumplimiento normativo: (i) la promoción, que se caracteriza por ser principalmente voluntario, que implica que se busquen incentivos atractivos a los agentes económicos para la implementación de tales programas como la reducción de multas; y, (ii) la imposición, que se destaca por ser obligatorio y forzoso para los agentes económicos que han infringido las normas.

Por una parte, para la promoción de los programas de cumplimiento normativo resulta necesaria la existencia de reglas claras y beneficios económicos definidos para incentivar a los agentes económicos para que voluntariamente opten por implementar tales programas. Ello, conociendo que su implementación no garantiza la imposibilidad de cometer una infracción.

Así, es prioritario que en materia de protección al consumidor y publicidad se conozca a nivel público las reglas aplicables para acogerse a un atenuante, así como el valor de los porcentajes que podrían reducirse de una eventual multa. Y, en materia de libre competencia, se podría evaluar la posibilidad de ampliar el valor de porcentaje de reducción de la multa. Ello, en tanto la promoción requiere la existencia de incentivos atractivos para los agentes económicos.

De otra parte, para la imposición de los programas de cumplimiento normativo a través de medidas correctivas, resulta necesaria una habilitación legal, así como la motivación necesaria que justifique que resulta ser la medida idónea para evitar que la conducta infractora ocurra en el futuro. En particular, dada su naturaleza de mandato, implica que sea razonable y ajustada a la intensidad, proporcionalidad y necesidades del bien jurídico tutelado.

De este modo, resulta claro que debido a que en materia de protección al consumidor y publicidad no existe una habilitación legal para su imposición como mandato de medida correctiva, sería necesaria una reforma normativa como aquella ocurrida en materia de libre competencia.

Finalmente, entre la promoción y la imposición de los programas de cumplimiento normativo, aquel que resulta más fiel a la naturaleza de tales programas ciertamente es a través de su fomento voluntario. Por ello, las entidades de la Administración Pública deberán redoblar esfuerzos para conseguirlo y no recurrir a métodos impositivos, los cuales se ordenan cuando se ha fracasado en promover el cumplimiento voluntario de las normas.

32. Por ejemplo, existen supuestos en que los agentes económicos son amenazados por sus competidores para participar en un cartel. En tales casos, podría considerarse que no resulta necesaria la implementación de los programas de cumplimiento normativo. 